\title{
0799 VIOLENCE EXPERIENCE AND QUALITY OF LIFE IN PRIMARY SCHOOLS IN HAMBURG, GERMANY
}

Z Schillmoeller*, M Erhart, U Ravens-Sieberer Correspondence: Department of Health Sciences, Faculty of Life Sciences, Hamburg University of Applied Sciences, Lohbruegger Kirchstrasse 65, Hamburg, 21033, Germany

10.1136/ip.2010.029215.799

Violence in schools (bullying) has repeatedly been in the focus of societal discussions. Public health studies were primarily conducted in secondary schools. This study is the first one in Germany which informs about experiences with violence, practicing violence and attitudes towards violence in primary school children in Hamburg.

In November 2005, a cross-sectional survey was conducted in which 1154 primary school children of the third and fourth grade answered a quantitative questionnaire concerning the above issues. In addition to bi- and multivariate analysis, Structural Equation Modelling was conducted to analyse the association between the main latent outcome variables bullying and quality of life.

The results show that bullying in primary schools is a common problem. $20 \%$ of the third and fourth graders reported having been bullied at least once a week. 5-7\% of children admitted to have bullied someone once a week. $25 \%$ of the school children reported feeling a low subjective quality of life. While school climate and social support by friends and peers was associated with bullying, gender and socioeconomic conditions did not show any significant association. Only 50\% of pupils reported that they would inform adults about their current bullying situation.

In conclusion, to improve the violence situation in schools factors influencing the school climate particularly the relationship between teachers and students, needs to be enhanced because these factors in turn influence the social support between the children, thereby preventing or decreasing bullying experiences and improving the subjective quality of life in children. 